\title{
Aptamers: Novel Molecules as Diagnostic Markers in Bacterial and Viral Infections?
}

\author{
Flávia M. Zimbres, ${ }^{1}$ Attila Tárnok, ${ }^{2}$ Henning Ulrich, ${ }^{3}$ and Carsten Wrenger ${ }^{1}$ \\ ${ }^{1}$ Unit for Drug Discovery, Department of Parasitology, Institute of Biomedical Science, University of São Paulo, \\ Avenida Professor Lineu Prestes 1374, 05508-000 São Paulo, SP, Brazil \\ ${ }^{2}$ Department of Pediatric Cardiology, Heart Centre Leipzig, Translational Centre for Regenerative Medicine (TRM), \\ University of Leipzig, Strümpellstraße 39, 04289 Leipzig, Germany \\ ${ }^{3}$ Department of Biochemistry, Institute of Chemistry, University of São Paulo, Avenida Professor Lineu Prestes 748, \\ 05508-900 São Paulo, SP, Brazil
}

Correspondence should be addressed to Henning Ulrich; henning@iq.usp.br and Carsten Wrenger; cwrenger@icb.usp.br

Received 6 June 2013; Accepted 30 July 2013

Academic Editor: Sudhish Mishra

Copyright (C) 2013 Flávia M. Zimbres et al. This is an open access article distributed under the Creative Commons Attribution License, which permits unrestricted use, distribution, and reproduction in any medium, provided the original work is properly cited.

\begin{abstract}
Worldwide the entire human population is at risk of infectious diseases of which a high degree is caused by pathogenic protozoans, worms, bacteria, and virus infections. Moreover the current medications against pathogenic agents are losing their efficacy due to increasing and even further spreading drug resistance. Therefore, there is an urgent need to discover novel diagnostic as well as therapeutic tools against infectious agents. In view of that, the Systematic Evolution of Ligands by Exponential Enrichment (SELEX) represents a powerful technology to target selectively pathogenic factors as well as entire bacteria or viruses. SELEX uses a large combinatorial oligonucleic acid library (DNA or RNA) which is processed a by high-flux in vitro screen of iterative cycles. The selected ligands, termed aptamers, are characterized by high specificity and affinity to their target molecule, which are already exploited in diagnostic and therapeutic applications. In this minireview we will discuss the current status of the SELEX technique applied on bacterial and viral pathogens.
\end{abstract}

\section{Introduction}

Due to the continuously rising number of the population as well as the emergence of resistances of human pathogenic organisms against the current treatment, there is an urgent need to develop novel diagnostic and-even furthertherapeutic tools to deal with the upcoming problems in the near future. Not only the development of new tools is mandatory but also-and becoming an even more prominent issue-the commercial value in terms of their costs. In this sense the discovery of novel technologies and moreover their subsequent applications have become important in laboratory and field studies. As an example, innovations in high-throughput single cell analysis for diagnostic purposes but also for functional analysis and drug discovery are today available in order to analyze pathogenic organisms such as the viruses Hepatitis C [1], influenza [2], or HIV [3] as well as bacteria like Mycobacterium tuberculosis [4] or
Staphylococcus aureus [5]. The SELEX technique (Systematic Evolution of Ligands by Exponential Enrichment) was originally discovered by Gold and Szostak [6, 7]. They were using reiterative in vitro selection for high-affinity oligonucleotide ligands (aptamers) against almost any kind of molecules which is of biological or therapeutic interest (for illustration see Figure 1). RNA and DNA aptamers recognize their targets with high specificity and affinity. These high-affinity ligands can be developed against almost any target through iterative cycles of in vitro screening of a combinatorial oligonucleotide library for target binding followed by their PCR amplification. SELEX procedures are characterised by employing random oligonucleotide libraries of up to $10^{12}-10^{15}$ different nucleic acid molecules, revealing an at least equivalent number of secondary and tertiary structures of their respective singlestranded nucleic acid molecules [8]. After their first round of in vitro selection against a chosen target molecule, the 


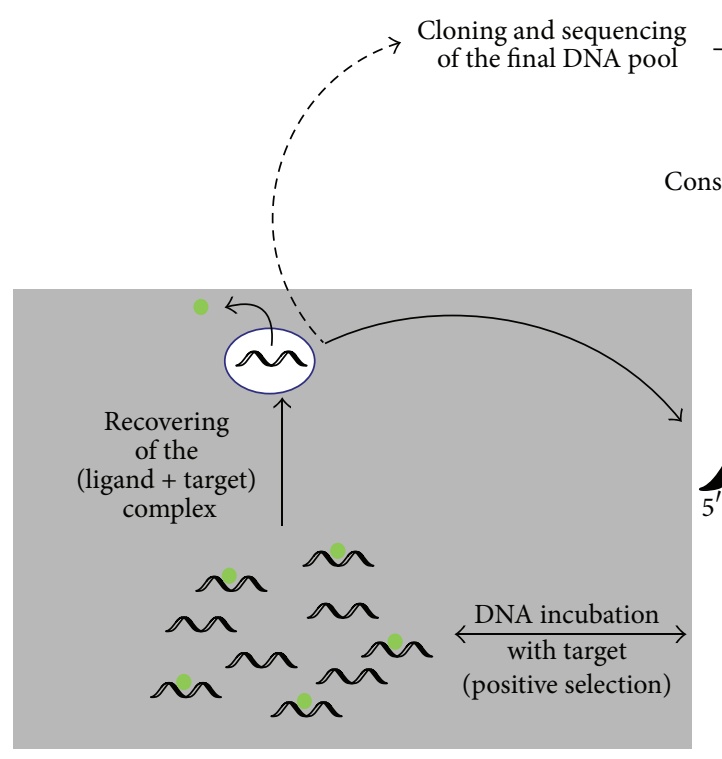

(a)
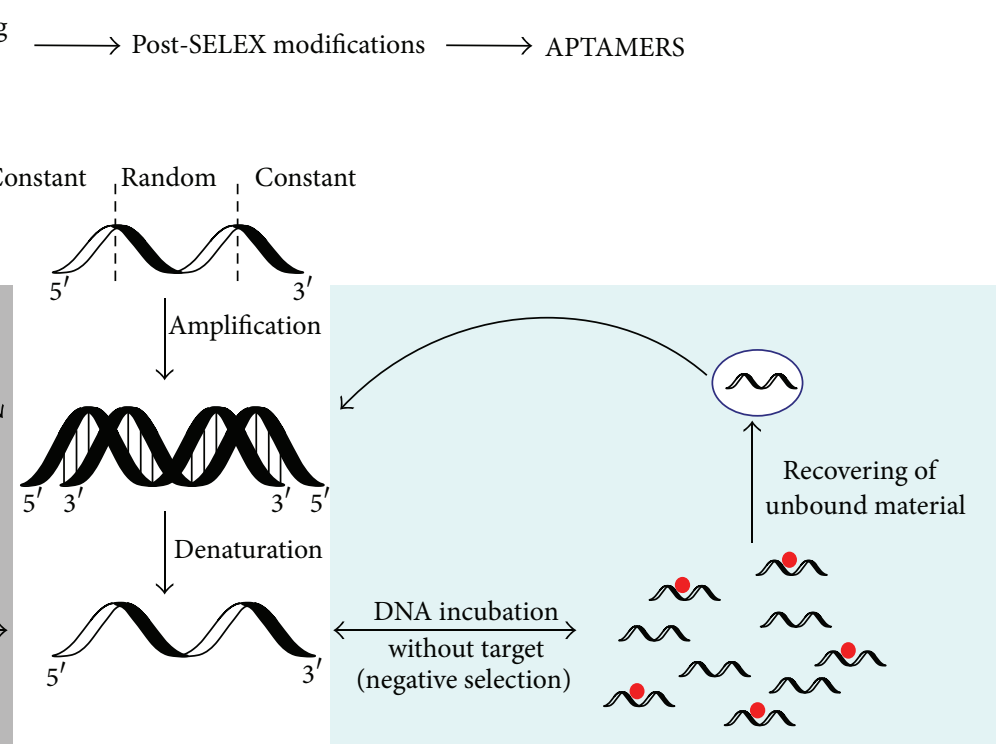

(b)

FIGURE 1: Schematic illustration of the SELEX methodology. The SELEX technique uses a large combinatorial oligonucleic acid library (DNA or RNA) consisting of an inner random region flanked by two constant regions. In the following, attention has solely been drawn on the development of DNA aptamers. The DNA library consisting of partially randomised DNA sequences (inner random region flanked on both sites by constant sequences) is amplified by conventional PCR. The derived double-stranded DNA is denatured and separated into singlestranded DNA by gel electrophoresis, the single-stranded DNA isolated and subsequently incubated with the respective target molecules ((a), positive selection). After incubation step, the formed target-aptamer-complex is separated from nonbinding aptamers and applied to PCR for amplification of the target-bound aptamers (grey panel). Eventually, (b) negatives cycles (blue panel) are also carried out to remove aptamers which bind unspecifically or not to the desired target molecules. As a resulting consequence, the unbound aptamers are recovered, amplified via PCR, and applied in the next (positive) selection cycle. Subsequently, from final selected library aptamer sequences are identified and aligned for the verification of consensus sequence motifs. If required post-SELEX modifications such as truncations, stabilizations, and covalent attachment of fluorescence reporters can be applied to optimize aptamers for any desired purpose.

eluted aptamers are amplified by PCR procedures to restore the DNA library for the next SELEX cycle. The number of cycles depends mainly on the affinity of the aptamertarget interactions as well as on the stringency imposed to each round of selection. After several rounds of iterative SELEX cycles, the aptamers are selected via their target molecules (positive selection step) (Figure 1). In case of not using highly pure target molecules, the library needs to be exposed to different or contaminating molecules for counterselection in order to discard these molecules (negative selection step) (Figure 1). Subsequently, the final selected library of high affinity aptamers are cloned and sequenced to identify respective consensus motifs, which are responsible for the secondary/tertiary structures interacting with the target molecule [9]. These structures comprise a variety of different conformations which include-among othersstem-loop structures. Comparisons between DNA or RNA stem-loops suggest that the structure of the DNA molecules can be slightly less stable. On the other hand-due the lacking ribose $2^{\prime}$-hydroxyl group-DNA is characterised by a greater flexibility and, consequently, leading to a higher diversity of structural conformations [10]. In contrast to DNA aptamers, RNA aptamers require reverse transcription prior amplification by PCR and in terms of their stability they might need modifications such as substitution of the $2^{\prime}$-OH group of ribose by $2^{\prime}$-amino, $2^{\prime}$-fluoride, or $\mathrm{O}$ methylene functions, to prolong their half-life in biological fluids $[11,12]$. Unlike RNA aptamers which are obliged to modifications in order to prevent RNAse accessibility, DNA aptamers do not need any modifications for their stability in various applications. Moreover, the latter one can be easily modified for the attachment of reporter molecules such as fluorescence dyes or biotin [13]. Those biotinylated aptamers can subsequently be applied in pull-down experiments using streptavidin-coated magnetic beads $[14,15]$ or to visualise targets using fluorescent reporters [16]. The binding properties of an aptamer are dictated by its sequence and the deriving folding into stem-loop structures (Figure 2) [13, 17]. Aptamertarget complexes often reveal low dissociation constants that range from nanomolar to picomolar levels $[9,18]$, which is comparable to those of monoclonal antibodies.

Moreover, aptamers are capable of distinguishing between protein isoforms [19] as well as different conformational forms of the same protein [20]. Furthermore, aptamers can be denatured and renatured by changing the temperature. Additionally they are generated by an iterative in vitro instead of an in vivo process as it is the case for animal-derived antibodies [16].

In the near future oligonucleotide-based high-affinity aptamers are expected to substitute antibodies in many applications, mostly due to their stability, nonpeptide character, and their independency from animal resources. Moreover, the beneficial characteristics of aptamers have already been 


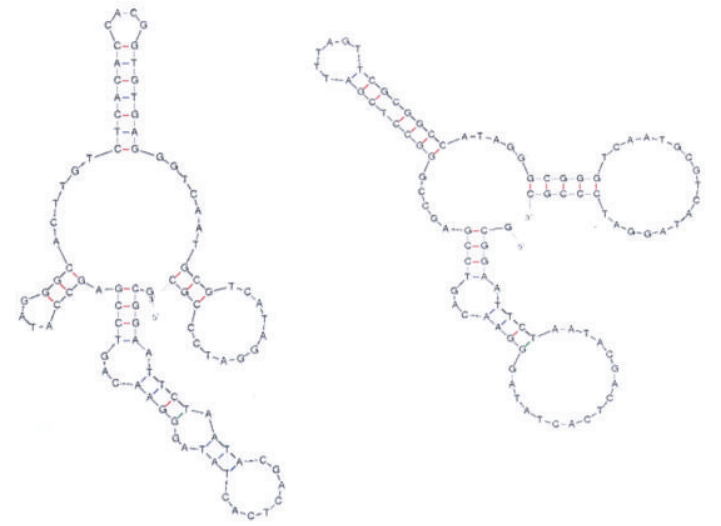

(a)

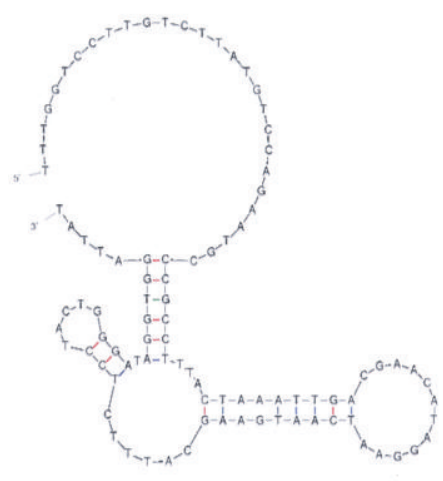

(b)

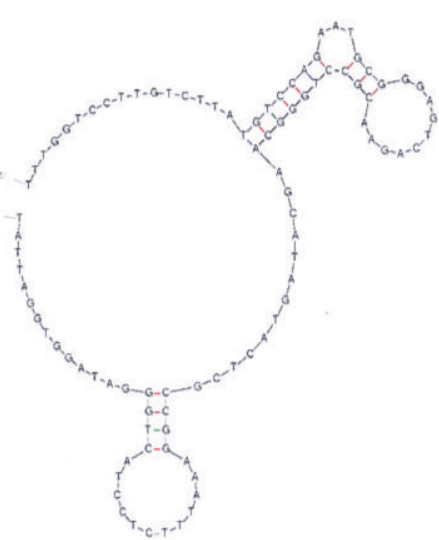

FIGURE 2: Predicted folding of selected single-stranded DNA aptamers. Stem-loop structures of aptamers play a fundamental role in target molecule binding. Respective consensus sequences of aptamers binding to (a) Hepatitis C virus (HCV) E2 glycoprotein on the cell surface [24] and (b) S. Typhimurium outer membrane proteins (OMPs) [25] were analyzed using the MFold programme [26] for secondary structure predictions.

exploited in the fight against infectious diseases as outlined below.

\section{Overview of Aptamer Applications in Human Infection Diseases}

Infectious diseases affect almost the entire mankind as well as animals. Furthermore, increasing levels of pathogen resistance against available drugs aggravate the state of health worldwide, particularly in developing countries, where infectious diseases are responsible for a high level of mortality and morbidity [21]. Moreover, the continuously growing population combined with the ongoing drug resistance forces scientific research to discover novel diagnostic tools as well as chemotherapeutics to deal with the future problems caused by pathogenic agents. Here, we will focus on the status of SELEX applications for combating bacterial and viral human infections.

\section{Aptamers and Bacterial Infections}

Tuberculosis, along with malaria and HIV, is a major public health problem affecting millions of people worldwide. Currently, only one vaccine against tuberculosis is existing which is the attenuated strain of Mycobacterium bovis "BCGbacillus Calmette-Guerin"; however, the vaccine has only limited efficacy in tuberculosis-endemic regions [22]. In 2007 Chen et al. [23] isolated an aptamer entitled NK2 with high affinity and specificity against membrane proteins that are present on the surface of the virulent $M$. tuberculosis stain H37Rv while not existing on BCG. Furthermore, the binding of the NK2 aptamer to H37Rv led CD4+ T cells to produce an increased level of IFN- $\gamma$, which is known to be a protective cytokine against $M$. tuberculosis infections. Analysis of the spleen of mice treated with the NK2 aptamer showed a lower bacterial number as the control [23]. These results underline the potency of the NK2 aptamer as an antimycobacterial agent (Table 1).

Another common bacterial infection is caused by Salmonellae which are significantly involved in food-borne illness. About $25 \%$ of all food-borne diarrhoea patients need hospitalisation. A major problem is salmonellosis caused by multidrug-resistant (MDR) strains such as Salmonella enterica serovar Typhimurium DT104 or S. enterica serovar Newport [27]. Salmonellae are also important bacterial pathogens in food animal species including cows [28], pigs [29], chickens [30], and turkeys [31]. In order to evaluate the potential of aptamers against $S$. enterica serovar Typhimurium multidrug-resistant (MDR) strains, the SELEX method using DNA aptamers was applied to the bacterial outer membrane proteins (OMPs) by performing counterselection against Escherichia coli OMPs and lipopolysaccharides (LPS) (negative selection step). Subsequently aptamers were identified which selectively interact only with the bacterial OMPs [25] (Table 1).

It is known that the invasion of IVB piliated S. enterica serovar Typhimurium A21-6 into human THP-1 monocytic cells reveals higher efficacy than that of a nonpiliated $S$. enterica serovar Typhimurium mutant strain. Consequently, approaches have been undertaken to interfere with the formation and accessibility of the type IVB pili. Thus, the SELEX technique was applied and single-stranded RNA aptamers were discovered that selectively bind to the pili and thereby hamper the infection of human THP-1 cells [32]. Analysis of the consensus sequence identified a stem-loop structure, which might be the possible binding site of the aptamer [32]. In summary, these RNA aptamers are considered as a novel agent for blocking bacterial pathogenesis (Table 1).

Bacteria such as $S$. aureus or E. coli are naturally present in humans. For example, $S$. aureus colonises permanently about $20 \%$ of healthy adults and up to $50 \%$ transiently. Its pathogenicity plays an important role in nosocomial infections affecting immunosuppressed patients. This pathogenic agent is responsible for a wide spectrum of diseases, which 
TABLE 1: Summary of aptamers against bacterial and viral human pathogens.

\begin{tabular}{|c|c|c|c|c|}
\hline Aptamers & Type of aptamer & Organism & Target & Reference \\
\hline NK2 & DNA aptamer & $\begin{array}{c}\text { Mycobacterium tuberculosis } \\
\text { (strain H37Rv) }\end{array}$ & Membrane proteins & {$[23]$} \\
\hline 33 & DNA aptamer & $\begin{array}{c}\text { Salmonella enterica serovar } \\
\text { Typhimurium }\end{array}$ & $\begin{array}{l}\text { Outer membrane proteins } \\
\text { (OMPs) }\end{array}$ & {$[25]$} \\
\hline S-PS8.4 & RNA aptamer & $\begin{array}{c}\text { Salmonella enterica serovar } \\
\text { Typhimurium }\end{array}$ & Type IVB pili & {$[32]$} \\
\hline $\begin{array}{l}\text { SA20, SA23, SA31, SA } 34 \text { and } \\
\text { SA } 43\end{array}$ & DNA aptamer & $\begin{array}{c}\text { Staphylococcus aureus } \\
\text { (strain MRSA) }\end{array}$ & Whole bacteria & {$[33]$} \\
\hline ZE2 & DNA aptamer & Hepatitis $\mathrm{C}$ virus & $\begin{array}{l}\text { HCV envelope surface } \\
\text { glycoprotein E2 }\end{array}$ & {$[24]$} \\
\hline $\begin{array}{l}\text { Sequence (1), aptamer } \\
\text { sequence (2), and aptamer } \\
\text { sequence (3) }\end{array}$ & DNA aptamer & Avian influenza virus H5N1 & Hemagglutinin & {$[34]$} \\
\hline FO21 and FO24 & DNA aptamer & Rabies virus (RABV) & $\begin{array}{l}\text { RABV-infected } \\
\text { BHK-21 cells }\end{array}$ & {$[35]$} \\
\hline A-1 and Ch A-1 & RNA aptamer & $\begin{array}{l}\text { Human immunodeficiency } \\
\text { virus type } 1 \text { (HIV-1) }\end{array}$ & gp120 & {$[36]$} \\
\hline RT1t49 & DNA aptamer & & & {$[37]$} \\
\hline $70.5,70.8,80.55,80.93$ and T1.1 & RNA aptamer & & & {$[38]$} \\
\hline $\begin{array}{l}\text { TPK isolates, TPK-like isolates } \\
\text { and non-TPK isolates }\end{array}$ & RNA aptamer & $\begin{array}{l}\text { Human immunodeficiency } \\
\text { virus type } 1 \text { (HIV-1) }\end{array}$ & Viral reverse transcriptase & {$[39]$} \\
\hline $\begin{array}{l}70.8,13,70.15,80.55,65,70.28 \\
70.28 \mathrm{t} 34 \text { and } 1.1\end{array}$ & RNA aptamer & & & {$[40]$} \\
\hline 1.1 and $1.3 \mathrm{a}$ & RNA aptamer & & & {$[41]$} \\
\hline
\end{tabular}

includes life-threatening conditions like pneumonia or endocarditis [42], and emerges as a major human pathogen due to methicillin-resistant $S$. aureus (MRSA) strains. These bacteria are known to produce potent protein toxins and to express cell-surface proteins that can bind to antibodies and thereby inactivate their function [43]. It is well established that bacteria can express different sets of molecules to precisely control their proliferation at different growth states [44, 45]. They can even undergo antigenic variations to escape the immune response of its host [46, 47]. In order to deal with these bacterial mechanisms, a whole set of specific markers have been developed by Cao and coworkers [33]. They obtained a panel of single-stranded DNA aptamers with high specificity and sensitivity against $S$. aureus. The derived aptamers were grouped into different families on the basis of sequence homology as well as similarity in their predicted secondary structure. Subsequently five aptamers were identified that recognised different molecular targets, and a combination of them had a much better effect than the application of individual aptamers in detecting different $S$. aureus strains. These results clearly demonstrate that a set of aptamers specific to one bacterium can be used as a highly selective diagnostic tool or even potentially to block the growth cycle of the pathogen [33].

\section{Aptamers in Viral Infections}

Hepatitis $\mathrm{C}$ is an infectious disease caused by the hepatitis $\mathrm{C}$ virus ( $\mathrm{HCV})$, which has infected about $3 \%$ of the world's population and induces in $80 \%$ of the infected people dysfunction of the liver, like cirrhosis. Presently, there is no efficient vaccine available, and the treatment of the infectious disease relies on the use of alpha interferon (IFN- $\alpha$ ) alone or in combination with ribavirin [48-50]. However, the rate of success is limited, and such treatments are expensive and bear the risk of serious side effects $[48,49,51]$. In order to discover new modes of detection and selective interference with the proliferation of the virus, the alive Cell SurfaceSystematic Evolution of Ligands by Exponential Enrichment (CS-SELEX) technique has been developed and subsequently used for selection of single-stranded DNA aptamers directed to the HCV envelope surface glycoprotein E2 [24]. A singlestranded DNA aptamer that specifically binds to the HCVE2 envelope glycoprotein was named ZE2. It is believed that the ZE2 aptamer competitively inhibits the HCV-E2 envelope glycoprotein by binding to CD81, an important $\mathrm{HCV}$ receptor, and significantly blocks $\mathrm{HCV}$ cell culture infection of human hepatocytes. Thereby, the ZE2 aptamer emphasizes its potency to act as a possible novel diagnostic and therapeutic candidate in HCV infections.

Avian influenza virus (AIV) H5N1, also known as "bird flu," is a type A influenza virus, responsible for major epidemics and pandemics. Therefore attention has been drawn-besides the use of other therapeutic tools-on the selection of aptamers against the $\mathrm{H} 5 \mathrm{~N} 1$ virus. Wang et al. [34] started with a single-stranded DNA library and performed the first rounds of selection cycles using purified hemagglutinin (HA) from AIV H5N1, and afterwards the 
entire $\mathrm{H} 5 \mathrm{~N} 1$ virus was used as a target. After various SELEX rounds of positive target selection and clearance of selected pools of oligonucleotides binding to nontarget AIV subtypes (H5N2, H5N3, H5N9, H7N2, H2N2, and H9N2), aptamers were cloned and sequenced. The found consensus sequences were analysed for predicted secondary structures, which led to the identification of hairpin loops and bulge loops that are suggested to play an important role in target binding. By using surface plasmon resonance, one aptamer was identified possessing a high binding capability with a dissociation constant of less than $5 \mathrm{nM}$ to the H5N1 virus.

Rabies is a zoonotic disease, which is caused by the rabies virus (RABV), and is transmitted through exposure to infected saliva during either a bite or direct contact with mucosal tissues. Infection with this virus results in an acute fatal encephalitis, leading to coma and death. This disease affects many warm-blooded mammals. Currently, no approved therapy is available once the clinical signs have appeared. By being a fatal disease in all instances, there is a strong incentive to develop a cheap and effective drug. In this sense aptamers were selected against RABV-infected cells using the Cell-SELEX technique [35]. These aptamers were subsequently applied to viral titre assays, which clearly demonstrated an inhibition of RABV-infected cell, while an inhibition of the canine distemper virus or canine parvovirus was not observed. Furthermore, in in vivo tests aptamers could protect mice to a certain extent from RABV infection. Interestingly, the selected aptamers were of protective nature because when mice were inoculated with aptamers before inoculation with CVS-11, only about $15 \%$ of the animals died, whereas almost no mice survived when aptamers were used for treatment [35].

Such as other pathogens, HIV is also characterised by the appearance of drug-resistant viruses. About 30 years ago, it was discovered that HIV contains several small RNA sequences or regions which can specifically bind to viral or cellular proteins with high affinity. Functional studies indicated that these viral RNA-protein complexes could be exploited in therapeutic approaches as demonstrated for small HIV RNA regions, termed TAR, that could be used to inhibit HIV virus replication in cellular models [52]. The envelope glycoprotein gp120 of the HIV-1 virus plays a fundamental role during infection of CD4-positive cells. Cell fusion is initiated by the interaction between gp120 and CD4 (Table 1). In view of this mechanism, RNA aptamers were generated, which bind selectively to the gp120 glycoprotein $[53,54]$. In a humanized mouse model where HIV-1 replication and T-cell depletion mimic the human situation, Neff and colleagues [36] found that the anti-gp120 aptamer suppressed HIV-1 replication and prevented thereby the viralmediated T-cell reduction.

The SELEX technique was also applied to the viral reverse transcriptase, which is essential for replication, and thereby RNA and DNA aptamers were identified that bound to multiple epitopes of the viral reverse transcriptase with high affinity and specificity $[37,38,55]$. Among those aptamers, pseudoknot RNAs have received attention which bind to the HIV-1 reverse transcriptase at a nanomolar level [39-41], abolish its catalytic activity [38], and inhibit HIV replication in cell culture $[40,56,57]$. These results clearly emphasize that aptamers binding to the HIV-1 reverse transcriptase are promising novel tools to be used in therapeutic interventions.

\section{Conclusion}

As outlined above bacterial and viral infection diseases are a major threat to humans. Considering that the current therapeutics are losing their efficacy, there is an urgent need to discover and develop novel medication and rapid diagnostic to deal with these diseases. In this sense the SELEX technology by using aptamers provides a powerful tool not only to identify novel diagnostic markers but also to interfere with the proliferation of these human pathogens [16]. The aptamer technique is already subject to a variety of clinical trials in human-related diseases [58]. A VEGF165-binding aptamer, Macugen, was recently commercialised as an antiangiogenic therapeutic agent for neovascular age-related macular eye disease $[59,60]$. Macugen has been a breakthrough in the therapeutic use of aptamers and encourages the development of further aptamers against infectious disease targets as outlined in this minireview and summarized in Table 1.

\section{Acknowledgments}

This work was financially supported by the Grants 2009/54325-2, 2010/20647-0, and 2011/19703-6 as well as the German-Brazilian Network project (Grant 2012/50393-6) of the Fundação de Amparo à Pesquisa do Estado de São Paulo (FAPESP) and the German Federal Ministry of Education and Research (BMBF, PtJ-Bio, 1315883).

\section{References}

[1] G. Shi, F. Yagyu, Y. Shimizu et al., "Flow cytometric assay using two fluorescent proteins for the function of the internal ribosome entry site of hepatitis C virus," Cytometry Part A, vol. 79, no. 8, pp. 653-660, 2011.

[2] F. Gondois-Rey, S. Granjeaud, S. L. T. Kieu, D. Herrera, I. Hirsch, and D. Olive, "Multiparametric cytometry for exploration of complex cellular dynamics," Cytometry Part A, vol. 81, no. 4, pp. 332-342, 2012.

[3] J. Pollara, L. Hart, F. Brewer et al., "High-throughput quantitative analysis of HIV-1 and SIV-specific ADCC-mediating antibody responses," Cytometry Part A, vol. 79, no. 8, pp. 603612, 2011.

[4] J. M. Mateos-Pérez, R. Redondo, R. Nava et al., "Comparative evaluation of autofocus algorithms for a real-time system for automatic detection of Mycobacterium tuberculosis," Cytometry Part A, vol. 81, no. 3, pp. 213-221, 2012.

[5] M. Ruger, G. Bensch, R. Tungler, and U. Reichl, "A flow cytometric method for viability assessment of Staphylococcus aureus and Burkholderia cepacia in mixed culture," Cytometry Part A, vol. 81, pp. 1055-1066, 2012.

[6] A. D. Ellington and J. W. Szostak, "In vitro selection of RNA molecules that bind specific ligands," Nature, vol. 346, no. 6287, pp. 818-822, 1990.

[7] C. Tuerk and L. Gold, "Systemic evolution of ligands by exponential enrichment: RNA ligands to bacteriophage T4 DNA polymerase," Science, vol. 249, no. 4968, pp. 505-510, 1990. 
[8] H. Ulrich, A. H. B. Martins, and J. B. Pesquero, "RNA and DNA aptamers in cytomics analysis," Current Protocols in Cytometry, vol. 7, pp. 1-39, 2005.

[9] H. Ulrich, A. H. B. Martins, and J. B. Pesquero, "RNA and DNA aptamers in cytomics analysis," Cytometry Part A, vol. 59, no. 2, pp. 220-231, 2004.

[10] K. Harada and A. D. Frankel, "Identification of two novel arginine binding DNAs," The EMBO Journal, vol. 14, no. 23, pp. 5798-5811, 1995.

[11] A. S. Davydova, M. A. Vorobjeva, and A. G. Venyaminova, "Escort aptamers: new tools for the targeted delivery of therapeutics into cells," Acta Naturae, vol. 3, pp. 12-29, 2011.

[12] E. W. M. Ng, D. T. Shima, P. Calias, E. T. Cunningham Jr., D. R. Guyer, and A. P. Adamis, "Pegaptanib, a targeted antiVEGF aptamer for ocular vascular disease," Nature Reviews Drug Discovery, vol. 5, no. 2, pp. 123-132, 2006.

[13] A. A. Nery, C. Wrenger, and H. Ulrich, "Recognition of biomarkers and cell-specific molecular signatures: aptamers as capture agents," Journal of Separation Science, vol. 32, no. 10, pp. 1523-1530, 2009.

[14] M. B. Murphy, S. T. Fuller, P. M. Richardson, and S. A. Doyle, "An improved method for the in vitro evolution of aptamers and applications in protein detection and purification," Nucleic Acids Research, vol. 31, no. 18, p. el10, 2003.

[15] J.-N. Rybak, S. B. Scheurer, D. Neri, and G. Elia, "Purification of biotinylated proteins on streptavidin resin: a protocol for quantitative elution," Proteomics, vol. 4, no. 8, pp. 2296-2299, 2004.

[16] H. Ulrich and C. Wrenger, "Disease-specific biomarker discovery by aptamers," Cytometry Part A, vol. 75, no. 9, pp. 727-733, 2009.

[17] M. Famulok, G. Mayer, and M. Blind, "Nucleic acid aptamersfrom selection in vitro to applications in vivo," Accounts of Chemical Research, vol. 33, no. 9, pp. 591-599, 2000.

[18] S. Tombelli, M. Minunni, and M. Mascini, "Analytical applications of aptamers," Biosensors and Bioelectronics, vol. 20, no. 12, pp. 2424-2434, 2005.

[19] R. Conrad and A. D. Ellington, "Detecting immobilized protein kinase C isozymes with RNA aptamers," Analytical Biochemistry, vol. 242, no. 2, pp. 261-265, 1996.

[20] S. Sekiya, F. Nishikawa, K. Noda, P. K. Kumar, T. Yokoyama, and S. Nishikawa, "In vitro selection of RNA aptamers against cellular and abnormal isoform of mouse prion protein," Nucleic Acids Symposium Series, no. 49, pp. 361-362, 2005.

[21] A. R. Renslo and J. H. McKerrow, "Drug discovery and development for neglected parasitic diseases," Nature Chemical Biology, vol. 2, no. 12, pp. 701-710, 2006.

[22] B. Bloom and P. Fine, "The BCG experience: implications for future vaccines against tuberculosis," in Tuberculosis: Pathogenesis, Protection and Control, B. R. Bloom, Ed., pp. 531-557, ASM Press, Washington, DC, USA, 1994.

[23] F. Chen, J. Zhou, F. Luo, A.-B. Mohammed, and X.-L. Zhang, "Aptamer from whole-bacterium SELEX as new therapeutic reagent against virulent Mycobacterium tuberculosis," Biochemical and Biophysical Research Communications, vol. 357, no. 3, pp. 743-748, 2007.

[24] F. Chen, Y. Hu, D. Li, H. Chen, and X.-L. Zhang, "CS-SELEX generates high-affinity ssDNA aptamers as molecular probes for hepatitis C virus envelope glycoprotein E2," PLoS ONE, vol. 4, no. 12, Article ID e8142, 2009.
[25] R. Joshi, H. Janagama, H. P. Dwivedi et al., "Selection, characterization, and application of DNA aptamers for the capture and detection of Salmonella enterica serovars," Molecular and Cellular Probes, vol. 23, no. 1, pp. 20-28, 2009.

[26] M. Zuker, "Mfold web server for nucleic acid folding and hybridization prediction," Nucleic Acids Research, vol. 31, no. 13, pp. 3406-3415, 2003.

[27] A. Gupta, J. Fontana, C. Crowe et al., "Emergence of multidrugresistant Salmonella enterica serotype Newport infections resistant to expanded-spectrum cephalosporins in the United States," Journal of Infectious Diseases, vol. 188, no. 11, pp. 17071716, 2003.

[28] S. J. Wells, P. J. Fedorka-Cray, D. A. Dargatz, K. Ferris, and A. Green, "Fecal shedding of Salmonella spp. by dairy cows on farm and at cull cow markets," Journal of Food Protection, vol. 64, no. 1, pp. 3-11, 2001.

[29] B. Malorny and J. Hoorfar, "Toward standardization of diagnostic PCR testing of fecal samples: lessons from the detection of salmonellae in pigs," Journal of Clinical Microbiology, vol. 43, no. 7, pp. 3033-3037, 2005.

[30] K. T. Carli, A. Eyigor, and V. Caner, "Prevalence of Salmonella serovars in chickens in Turkey," Journal of Food Protection, vol. 64, no. 11, pp. 1832-1835, 2001.

[31] R. Nayak, P. B. Kenney, J. Keswani, and C. Ritz, "Isolation and characterisation of Salmonella in a turkey production facility," British Poultry Science, vol. 44, no. 2, pp. 192-202, 2003.

[32] Q. Pan, X.-L. Zhang, H.-Y. Wu et al., "Aptamers that preferentially bind type IVB pili and inhibit human monocytic-cell invasion by Salmonella enterica serovar typhi," Antimicrobial Agents and Chemotherapy, vol. 49, no. 10, pp. 4052-4060, 2005.

[33] X. Cao, S. Li, L. Chen et al., "Combining use of a panel of ssDNA aptamers in the detection of Staphylococcus aureus," Nucleic Acids Research, vol. 37, no. 14, pp. 4621-4628, 2009.

[34] R. Wang, J. Zhao, T. Jiang et al., "Selection and characterization of DNA aptamers for use in detection of avian influenza virus H5N1," Journal of Virological Methods, vol. 189, pp. 362-369, 2013.

[35] H. R. Liang, Q. Liu, X. X. Zheng et al., “Aptamers targeting rabies virus-infected cells inhibit viral replication both in vitro and in vivo," Virus Research, vol. 173, no. 2, pp. 398-403, 2013.

[36] C. P. Neff, J. Zhou, L. Remling et al., "An aptamer-siRNA chimera suppresses HIV-1 viral loads and protects from helper $\mathrm{CD}^{+} \mathrm{T}$ cell decline in humanized mice," Science Translational Medicine, vol. 3, no. 66, Article ID 66ra6, 2011.

[37] T. S. Fisher, P. Joshi, and V. R. Prasad, "Mutations that confer resistance to template-analog inhibitors of human immunodeficiency virus (HIV) type 1 reverse transcriptase lead to severe defects in HIV replication," Journal of Virology, vol. 76, no. 8, pp. 4068-4072, 2002.

[38] D. M. Held, J. D. Kissel, D. Saran, D. Michalowski, and D. H. Burke, "Differential susceptibility of HIV-1 reverse transcriptase to inhibition by RNA aptamers in enzymatic reactions monitoring specific steps during genome replication," Journal of Biological Chemistry, vol. 281, no. 35, pp. 25712-25722, 2006.

[39] D. H. Burke, L. Scates, K. Andrews, and L. Gold, "Bent pseudoknots and novel RNA inhibitors of type 1 human immunodeficiency virus (HIV-1) reverse transcriptase," Journal of Molecular Biology, vol. 264, no. 4, pp. 650-666, 1996.

[40] P. Joshi and V. R. Prasad, "Potent inhibition of human immunodeficiency virus type 1 replication by template analog reverse transcriptase inhibitors derived by SELEX (systematic evolution 
of ligands by exponential enrichment)," Journal of Virology, vol. 76, no. 13, pp. 6545-6557, 2002.

[41] C. Tuerk, S. MacDougal, and L. Gold, "RNA pseudoknots that inhibit human immunodeficiency virus type 1 reverse transcriptase," Proceedings of the National Academy of Sciences of the United States of America, vol. 89, no. 15, pp. 6988-6992, 1992.

[42] F. D. Lowy, "Medical progress: Staphylococcus aureus infections," The New England Journal of Medicine, vol. 339, no. 8, pp. 520-532, 1998.

[43] N. M. Qtaishat, H. A. Gussin, and D. R. Pepperberg, "Cysteineterminated B-domain of Staphylococcus aureus protein A as a scaffold for targeting GABA(A) receptors," Analytical Biochemistry, vol. 432, pp. 49-57, 2013.

[44] D. Beier and R. Gross, "Regulation of bacterial virulence by twocomponent systems," Current Opinion in Microbiology, vol. 9, no. 2, pp. 143-152, 2006.

[45] S. Bronner, H. Monteil, and G. Prévost, "Regulation of virulence determinants in Staphylococcus aureus: complexity and applications," FEMS Microbiology Reviews, vol. 28, no. 2, pp. 183-200, 2004.

[46] A. Loughman, T. Sweeney, F. M. Keane, G. Pietrocola, P. Speziale, and T. J. Foster, "Sequence diversity in the A domain of Staphylococcus aureus fibronectin-binding protein A," BMC Microbiology, vol. 8, article 74, 2008.

[47] M. W. van der Woude and A. J. Bäumler, "Phase and antigenic variation in bacteria," Clinical Microbiology Reviews, vol. 17, no. 3, pp. 581-611, 2004.

[48] P. Bellecave and D. Moradpour, "A fresh look at interferonalpha signaling and treatment outcomes in chronic hepatitis C," Hepatology, vol. 48, pp. 1330-1333, 2008.

[49] N. Boyer and P. Marcellin, "Pathogenesis, diagnosis and management of hepatitis C," Journal of Hepatology, vol. 32, no. 1, pp. 98-112, 2000.

[50] C. H. Liu, C. J. Liu, C. L. Lin et al., "Pegylated interferon-alpha2a plus ribavirin for treatment-naive Asian patients with hepatitis $\mathrm{C}$ virus genotype 1 infection: a multicenter, randomized controlled trial," Clinical Infectious Diseases, vol. 47, pp. 12601269, 2008.

[51] M. Sarasin-Filipowicz, E. J. Oakeley, F. H. T. Duong et al., "Interferon signaling and treatment outcome in chronic hepatitis C," Proceedings of the National Academy of Sciences of the United States of America, vol. 105, no. 19, pp. 7034-7039, 2008.

[52] B. A. Sullenger, H. F. Gallardo, G. E. Ungers, and E. Gilboa, "Overexpression of TAR sequences renders cells resistant to human immunodeficiency virus replication," Cell, vol. 63, no. 3, pp. 601-608, 1990.

[53] A. K. Dey, M. Khati, M. Tang, R. Wyatt, S. M. Lea, and W. James, "An aptamer that neutralizes R5 strains of human immunodeficiency virus type 1 blocks gp120-CCR5 interaction," Journal of Virology, vol. 79, no. 21, pp. 13806-13810, 2005.

[54] M. Khati, M. Schüman, J. Ibrahim, Q. Sattentau, S. Gordon, and W. James, "Neutralization of infectivity of diverse R5 clinical isolates of human immunodeficiency virus type 1 by gp120binding $2^{\prime}$ F-RNA aptamers," Journal of Virology, vol. 77, no. 23, pp. 12692-12698, 2003.

[55] J. Jaeger, T. Restle, and T. A. Steitz, "The structure of HIV-1 reverse transcriptase complexed with an RNA pseudoknot inhibitor," The EMBO Journal, vol. 17, no. 15, pp. 4535-4542, 1998.

[56] L. Chaloin, M. J. Lehmann, G. Sczakiel, and T. Restle, "Endogenous expression of a high-affinity pseudoknot RNA aptamer suppresses replication of HIV-1," Nucleic Acids Research, vol. 30, no. 18, pp. 4001-4008, 2002.

[57] M. J. Lange, T. K. Sharma, A. S. Whatley et al., "Robust suppression of HIV replication by intracellularly expressed reverse transcriptase aptamers is independent of ribozyme processing," Molecular Therapy, vol. 20, pp. 2304-2314, 2012.

[58] H. Ulrich and C. Wrenger, "Identification of aptamers as specific binders and modulators of cell-surface receptor activity," Methods in Molecular Biology, vol. 986, pp. 17-39, 2013.

[59] N. Ferrara, H.-P. Gerber, and J. LeCouter, "The biology of VEGF and its receptors," Nature Medicine, vol. 9, no. 6, pp. 669-676, 2003.

[60] J. Ruckman, L. S. Green, J. Beeson et al., " 2 '-fluoropyrimidine RNA-based aptamers to the 165-amino acid form of vascular endothelial growth factor (VEGF165): inhibition of receptor binding and VEGF-induced vascular permeability through interactions requiring the exon 7-encoded domain," Journal of Biological Chemistry, vol. 273, no. 32, pp. 20556-20567, 1998. 

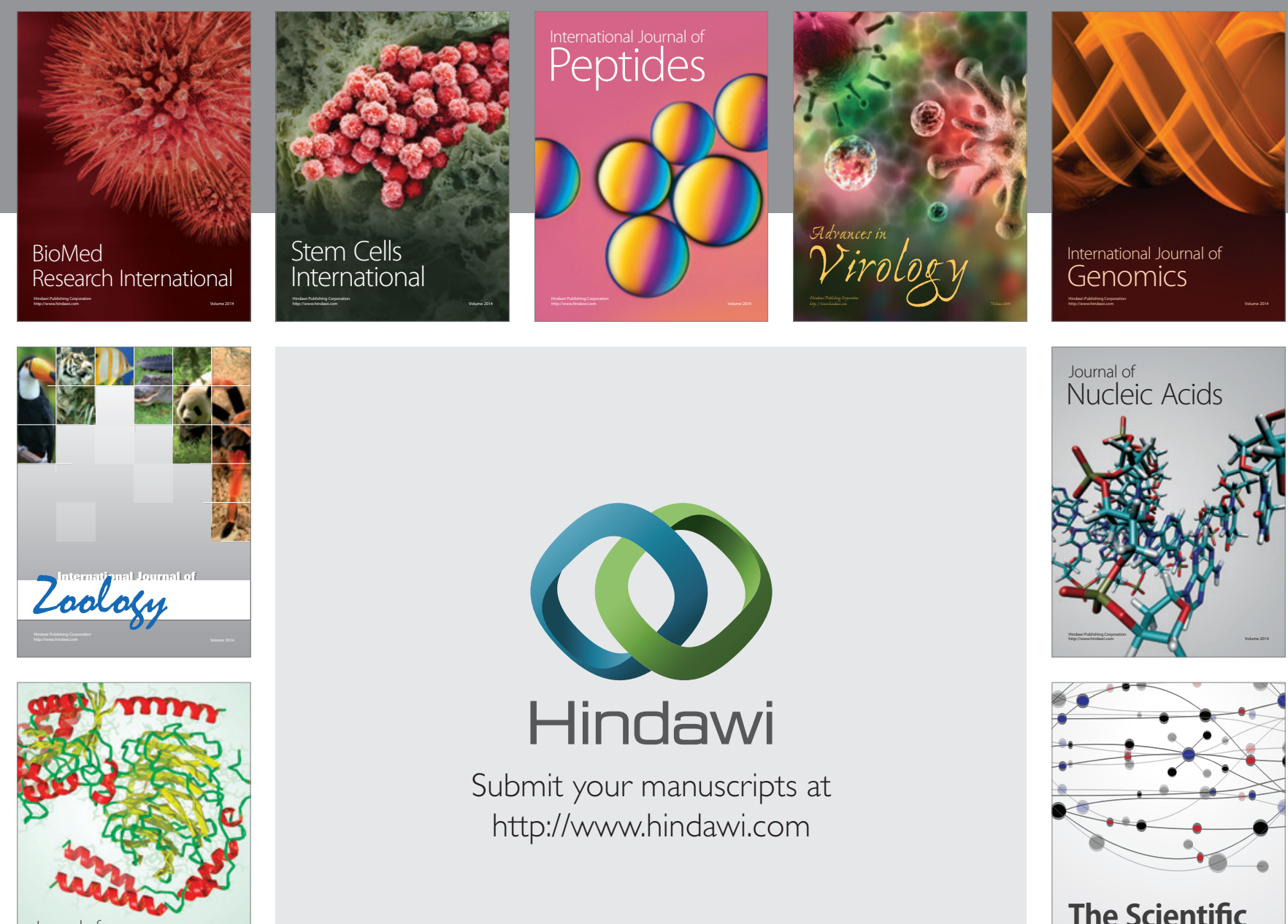

Submit your manuscripts at

http://www.hindawi.com

Journal of
Signal Transduction
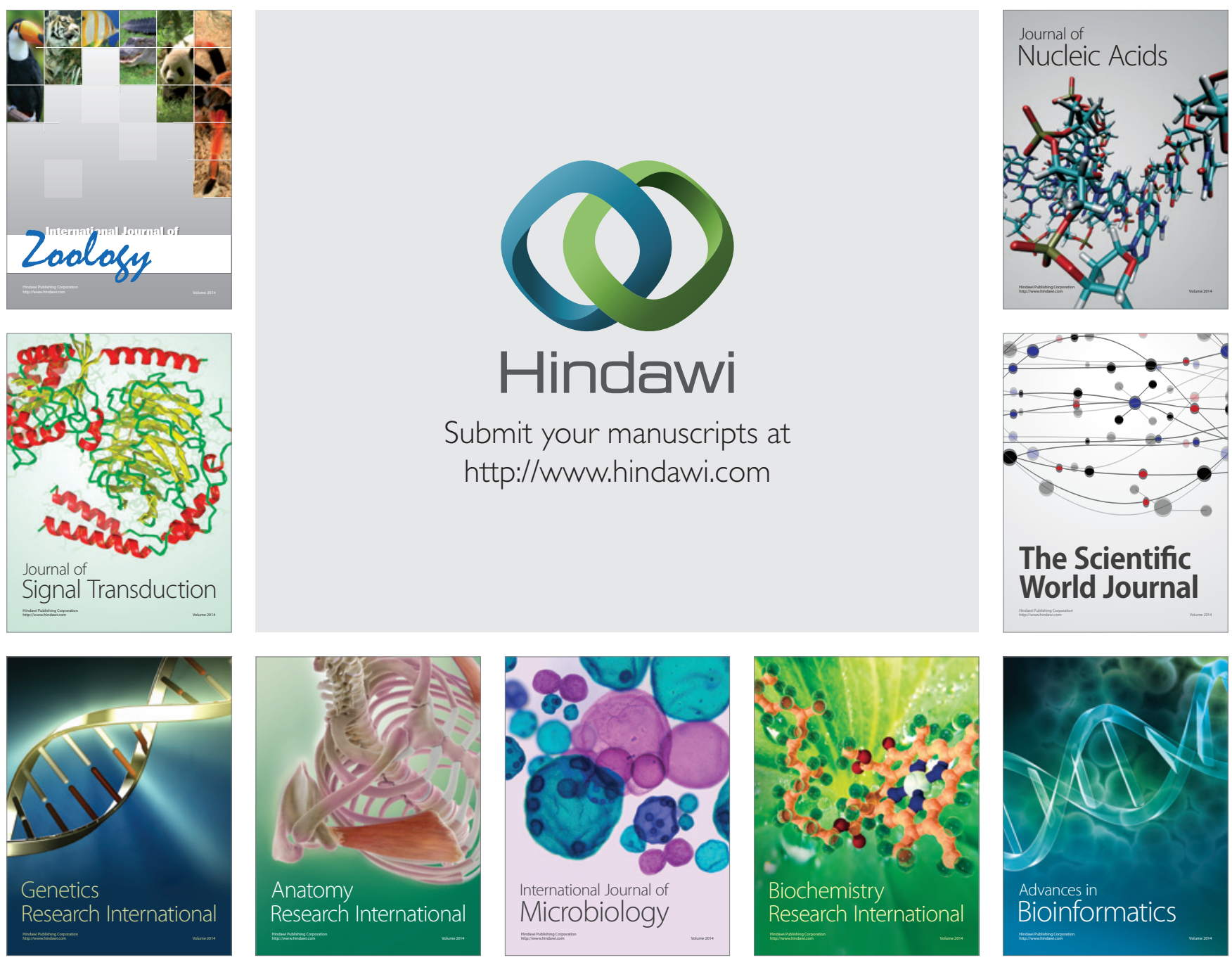

The Scientific World Journal
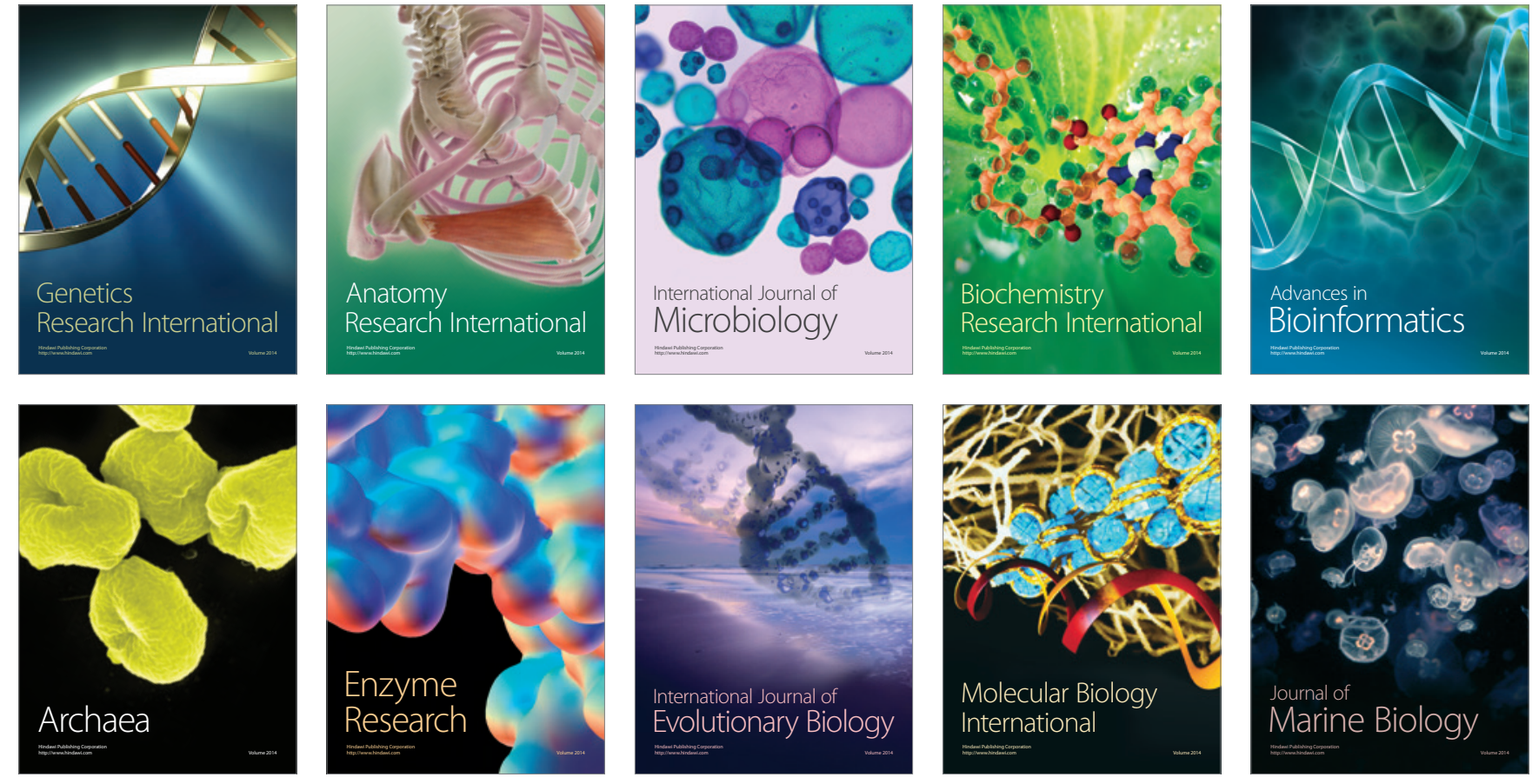